\title{
The Multicultural Liaison Officers' Perspective in Assessing Refugee Children in the Schools
}

\begin{abstract}
Any assessment, psychological, educational or speech and language, even in the native language, may pose many challenges for refugee children and their families in the schools. The Multicultural Liaison Officers are based at the schools to help families in dealing with a neweducational system. One of the areas the MLOs play a major role is in assisting the schools in assessing students. This article examines the involvement of the Multicultural Liaison Officers and their perspectives on assessing refugee children with disabilities as well as some of the obstacles and possibilities the families and the professionals face in dealing with this process.
\end{abstract}

\section{Résumé}

Toute évaluation, qu'elle soit psychologique, pédagogique ou d'élocution et de langage, même dans la langue maternelle, peut poser bien des défis aux enfants réfugiés et à leurs familles dans les écoles. Les agents de liaison multiculturels $(A L M)$ sont basés dans les écoles pour aider les familles à faire face au défi d'un système éducatif nouveau. Un des domaines où les ALM jouent un rôle important est dans l'aide qu'ils apportent aux écoles pour l'évaluation des élèves. Cet article examine la participation des ALMet leurs optiques propres sur l'évaluation des enfants réfugiés souffrant d'handicaps, ainsi que les obstacles et les possibilités auxquels les

Afarin Beglari, M.S., Certified Translator and Multicultural Liaison Officer, Ottawa Board of Education \& Ottawa-Carleton Immigrant Services Organization (OCISO). Her experience includes teaching at the university level.

Huong Thai, B.A., Ottawa Board of Education $\mathcal{E}$ Ottawa-Carleton Immigrant Services Organization (OCISO). Huong's various and extensive work experiences include working in refugee camps in Hong Kong for the United Nations High Commissioner for Refugees. For the past 8 years, Huong has been working as a Multicultural Liaison Officer at the schools.

\section{Afarin Beglari and Huong Thai}

familles et les professionnels ont à faire face pendant ce processus.

\section{Introduction}

The Multicultural Liaison Programme was launched in 1991 as a project between the Ottawa-Carleton Immigrant Services Organization and the former Ottawa Board of Education, now called Ottawa-Carleton DistrictSchool Board. The Multicultural Liaison Officers (MLOs) are based at the schools to assist refugee children and youth in adapting to their new school environment; to get parents involved in their children's education; and to help school staff learn about the different cultural backgrounds of refugee students. The MLOs provide services in areas of translation, referrals, orientation, advocacy and mediation, to name a few. We also work with the schools in assessing students as well as explaining the results and processes to the parents.

When a student is referred for assistance, one or more different types of assessments may be used in order to identify special needs such as educational, psychological, speech or language. The assessmentsmay include: a) gathering information about the student from the parents and professionals; b) observing the student in the school or classroom setting; c) examining a student's school work; and d) most often, doing informal or formal testing. Some assessments may indicate that the student's learning needs require the intervention of an Identification, Placement and Review Committee (IPRC). For the past eight years, as Multicultural Liaison Officers, we have been involved in many IPRCs as well as in first language assessments with students from Viet Nam, Iran, Afghanistan, among others (the entire team of MLOs speaks more than 25 languages).

The method and instruments used with the IPRC has been designed in North America but, for many reasons, this method may not meet the needs of children born and raised in other parts of the world-the Middle East, Africa, Latin America or Asia. Factors such as religion, race, ethnicity and language have not been taken into consideration when designing these instruments. In language assessment tests, for example, the level of difficulty of the vocabulary designated for a particular grade level for native born students may not necessarily match that of students who are speakers of other languages. In other words, vocabulary that is considered appropriate for a first grader in Iran may be appropriate for a fourth or fifth grader in Canada and vice versa. Consequently, standardized tests may not have been designed with the intent of accommodating the diversity of the school population. Several cases are discussed to illustrate some of the difficulties we encounter. We hope these cases help professionals working with refugee children and their families in understanding some of the cultural and linguistic challenges in service delivery.

\section{Cultural Interpretation in Assessing Children with Disabilities}

Since many refugees come from countries where there is no delivery of services for children with disabilities, we face several challenges. There are other factors at play, in particular, cultural perceptions of disabilities. For instance, parents may not seek services that their child may need because, in their culture, a child with a disability is viewed as a punishment from God. Therefore, their first response may be to hide the child. In some Middle Eastern cultures, families with children with physical or mental disabilities are also stigmatized. For Buddhists, a disability is attributed to Karma (the law of cause and effect) for something done in a past life. Nonetheless, the family and the community are 
expected to treat the child with care and compassion to avoid acquiring more Karma in the present life. Thus, difficulties inevitably arise when there is a great deal of diversity within a classroom.

For teachers, the increase in the number of minority students in our school system demands from an effective educator a better understanding and acceptance of differences, especially of children with disabilities. Frustration often occurs when teachers and students feel that they are not communicating or being understood. For instance, a student from Viet Nam was asked to produce a paragraph on Christmas. Instead, he sat there for 30 minutes not writing anything down. This happened because the boy does not celebrate Christmas at home thus hehas no experience of Christmas after being in Canada for only a short time. MLOs play a role in bridging these gaps. To illustrate some of the common barriers encountered, we present the following cases.

\section{Case 1: A Child with Hearing and Speech Challenges}

"It was in an elementary school when I attended the IPRC for this girl from Iran. She was seven years old and had been diagnosed with hearing and speech disorders." The special education teacher had worked with her individually through the school year. However, after a number of months, there was not much improvement observed. Although her parents were very cooperative and had tried their best to help, the child had not made any progress. Instead, shehad become very stressed and irritated. An IPRC was necessary to decide her placement. The IPRC team made up of a school psychologist, a social worker, the principal, the teacher, the parents and the MLO attended the meeting. "I was involved to help translate the results of the assessment to the parents."

"This kind of meeting was new to the parents since in their home country they had never been asked to attend such meetings, especially one that involved so many people. Thus, when they were asked to express their views, they had none. They only indicated, "We have done our best to follow the teacher's instructions and have practiced with our daughter all the words and phrases that were sent home" as they had agreed prior to this meeting. One thing was clear though, when the teacher sent home pictures of different objects and asked the parents to practice them with their daughter, the parents followed the teacher's recommendations. "It was not until I made a home visit, that I discovered that, not only did the parents not speak any English, but that they were practicing the vocabulary in Farsi and Kurdish." Meanwhile at school, the teacher practiced and spoke to her only in English. This miscommunication between home and school had caused the poor girl so much confusion that she had become terribly stressed and no one knew why. Meanwhile, the parents had worried that, maybe, their daughter was having some kind of mental disorders.

This case, on one hand, was resolved once the parents understood what the problem was. On the other, the school gave up hope of the parents helping the child since they did not have the English skills to help her. Based on this case, school officials and the MLOs concluded that training for parents with children with disabilities is necessary. Especially in need of such training are newly arrived families for whom the life style, school system, the views and services on disability are so different. The principal, at the suggestion of the MLO, recognized the need to offer sign language classes for parents. In fact, a class was set up. The problem then was the cost because parents could not afford the course. The option was then left up to teachers to teach a few sessions to the parents on a voluntary basis. Although the students could communicate with the teachers, the parents were not served when, due to budgetcuts more demands were placed on teachers.

\section{Case 2: A Boy with Learning Disabilities, Mainstream or Exclusion?}

A more recent case involved, Peter (a fictitious name), a twelve year old boy who had been diagnosed with learning disabilities and behavioral problems. The school had given him all the necessary tests and an IPRC was arranged to decide whether to send him to a school that offered a special education programme. After giving the explanations to the parents, they stated that there was nothing wrong with their son. According to the parents the reason for being a slow learner was that he had no help or support at home since both parents are illiterate and do not speak any English. The parents said that their son felt miserable and insisted that what he needed was a private tutor. Unfortunately, the parents could not afford one.

Wealso learnt from talking to the parents that the boy was very shy and because he was not able to speak English, he felt isolated and had no friends at his first school. One way he used to break his isolation was to get involved with a group of students who often get in trouble for their mischievous acts as a way to attract attention because of their lack of English proficiency. Peter expressed his frustration with his inability to speak English by being disruptive.

In September of 1999, Peter was sent to another school with a special education programme in a class with only eight students. Since this school was far away from home, the school arranged for a taxi to pick him up to and from home. To complicate matters, heshared the taxi with three other students who had profound physical and mental disabilities who were also his classmates. This presented several problems for the boy and for the family.

Peter tolerated that school for only one week. He refused to go no matter how hard his parents tried to send him back. His excuse was that he did not want to be placed in the sameclassroom with children whohad mental or physical disabilities "because my friends [and the neighbours] are calling me retarded." His parents also admitted that 
they were suffering from the same problem in the neighbourhoods. According to the parents, every time the taxi arrived, neighbours who were from the same country, "point at our son, and call him names." Furthermore, the parents noticed that "He has also started making funny gestures and unusual sounds imitating the children who are in his class."

The boy insisted thathe wanted to go back to his old school and be with his friends. "A second meeting was arranged and I was also asked to be involved." The parents admitted that the second school with only eight students in the class would certainly be a better place for their son. However, they preferred for Peter to go to the school near home where he could attend school with his friends rather than with the students who had developmental delays. Because disabilities carry a stigma in some cultures, the family responded: "Our reputation is at risk and we cannot ignore it." The principal of the school made them understand that by this decision, their child would no doubt fail as he would be placed in an ESL class with 25 other students. In this situation, the teacher would not be able to give extra attention to his individual needs.

In late January 2000 , a meeting was held to discuss Peter's situation. The case is partly resolved, though. After missing school for two weeks, Peter is attending the special education school, because the principal sent him back with the promise that he has to stay there for only one year. At the meeting, Peter's progress was discussed. In fact, he has shown improvements both academically and behaviourally. Since his behaviour is really noticeable in a class of eight, appropriate response and fast response in a small setting has helped. The parent's situation remains unresolved. They still feel ashamed since they are still not convinced that the special education programme was better for their son. Surrounded by their ethnocultural community, they feel especially helpless to help Peter, because the principal was not welcoming and demonstrated no empathy towards the circumstances of this family. For now, Peter seems to be doing satisfactorily.

\section{Case 3: A Child with Autism Whose Needs Got Lost in the Refugee Journey}

"I have been helping a family whose child has autism." The family had moved three times before coming to Ottawa. Because of the moves, the boy had never been in school nor had he ever been diagnosed with autism. Mom brought John (a fictitious name) who was eight years old to a school near home for registration and, poor John, was placed in a regular class. The teacher immediately noticed the difference in him from other students. She suspected autism but there were no documents from home or from his family doctor. She put his name in to be tested and within a week, John was placed in a school for children who have special needs. Because of John's severe autism, he was lucky to be tested so quickly. In other cases testing and the entire process of seeking a proper placement takes months.

Besides getting the support from the school, John also receives care from the Children Treatment Centre and the Infant Development Programme. They provide speech therapy, nutrition counselling and physiotherapy. A coordinator makes arrangements with the professionals and John's Mom. "Mom feels very fortunate to get help from everybody. However, due tocultural and language barriers, Mom finds it difficult remembering 'who is who and 'what kind of help her child is getting.'" She feels overwhelmed with the number of professionals coming to her home givingher ideas and suggestions on how to work with her child. This is very common with many of our families who struggle to cope in a new homeland. They may not be able to remember the names of the people or the agencies that have visited them. Professionals also find it difficult to clarify what contact a family has had and with what agencies. Unknowingly, the agencies may be duplicating services.

"Another difficulty in working with Mom is that she is illiterate." Many of the things the specialists suggest her to do may be beyond her comprehension.
For example, the specialists tell her to "have eye contact when she speaks to him, repeat words over and over again, play with him by using toys, etc. Mom had tried once but gave up because the tasks are too overwhelming." On one hand, the specialists feel that Mom is not willing to participate. On the other, Mom expects them to do it all, because she comes from a culture that holds professionals in high esteem. Clearly, it is difficult for Mom to understand the complexity of treatment for a child with autism. Patience is required to help her learn why such strategies are necessary to help her son. Professionals also need to understand that Mom comes from a culture that defers to professionals. "I helped her by explaining that she needs to be involved in her child's development by just taking a few minutes out of her busy schedule to work with her son." This effort will need time and patience. "Mom needs to look at it as a learning process for both the boy and for her."

Specialists also need to understand that everything is new for Mom and they need to give her time to learn new concepts and strategies for working with a child with autism. Home visits from so many professionals working with the family for whom "saving face" is so important has been just as challenging. Gradually, though "Mom is learning to take part and the trust we have built over time is paying off. John is doing very well at school and Mom is now enrolled in an ESL class full time."

\section{Reflections on Cultural Interpretation}

From our experience working as Multicultural Liaison Officers in the schools for the past eight years, we find that culture and language are the major barriers to communication. Using direct translation to explain the results of the assessment most often does not work. It is important that the cultural interpreter be familiar with the school system and with assessment instruments and procedures. It is also important to keep in mind that the cultural interpreter does not only interpret but his or her role is to help explain the client's values, practices, feelings and be- 
liefs. These factors will not surface if only direct translation is done. If the interpreter is not familiar with an assessment procedure, there should be a briefing prior to the assessment. In this meeting, the assessor would have the opportunity toexplain to the interpreter what to expect and what will transpire in the assessment process. Likewise, debriefing is essential. In this phase, interpreters should share with the assessor observations and comments regarding cultural values, beliefs, or norms that may influence the assessment process. Such information can be valuable when writing up the report and in making recommendations as well as considering the parents' perspective.

I have an example from one report done by a speech and language therapist on a third grade student. The therapist found that this student had difficulty in forming and reproducing sounds. She also had trouble with consonant blends, decoding and phonics, in general. If direct translation had been used to explain to the parents, they would not have understood what these terms meant, much less the purpose of the assessment. In situations such as this, the cultural interpreter should ask the assessor to give examples of the sounds or consonant blends that the child needs to practice. This way, the parents know exactly what you are talking about. With simple but useful examples, parents can work with the child at home concentrating on specific tasks.

Another obstacle that we often see is that many refugee families, especially recent arrivals, may not feel comfortable admitting that they do not understand what is being explained. Some nod and say "yes," giving the impression to teachers or professionals that they understand, when in fact, they are just being polite. It is crucial that the interpreter tactfully ask questions that will demonstrate the parents' comprehension during the meeting to avoid possi- ble misunderstandings. Interpreters may also have to explain important information and unfamiliar terms such as IPRC, names of devices and what various specialists do. This may need to be done several times or as many as it is necessary for them to grasp the concepts. To facilitate interactions and communication, it is helpful to teach the families to pronounce the names of the professionals involved with whom they will have the most contact. If possible, to protect the trust built over a period of time, it is important to be consistent in using the same interpreter.

\section{Conclusion}

Assessing refugee students in the schools is one of the many challenges we face daily. Factors such as the student's heritage, the impact of culture on the student's development, barriers to communication and the willingness of the professionals to be culturally sensitive to the needs of the families, have to be taken into consideration. To do assessments more effectively, we need to be more flexible by acknowledging stereotypes and assumptions. A common stereotype is that parents do not care about their children's education. However, our experience shows that, in fact, parents care but do not know how to access services that may be available. We also need to become more aware of other cultures, which will help us learn to accept other people's own cultural backgrounds and beliefs. An assessment process can be an overwhelming experience for students and parents that can cause stress, anxiety, uncertainty, fear and even mistrust. By encouraging constructive communication about differences as well as taking time to deal with cultural and language concerns, we can learn from one another. Professionals can do their job with more ease, but most of all, with understanding and respect for their clients' perspective. This approach can benefit the families and serve the children well in this challenging process.

\section{Feedback?}

\section{Questions ?}

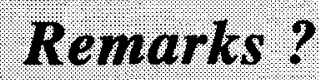

\section{Tre \\ welcome

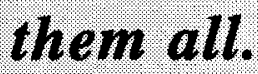

\section{Send to}

\section{refuge@viruca}

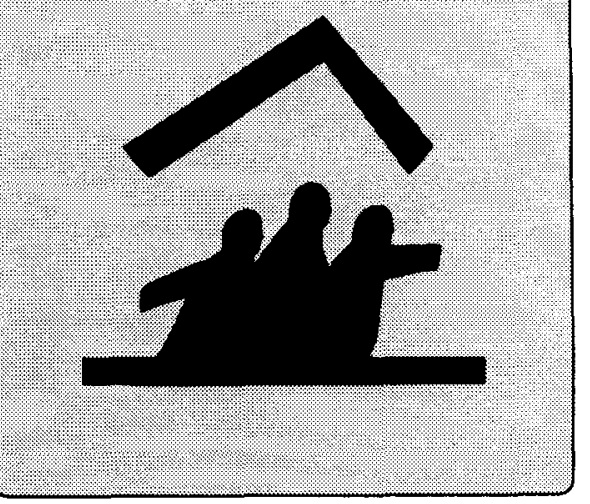

